\title{
Experimental Study about the Hysteretic Performance of the Pall-typed Piezoelectric Friction Damper
}

\author{
Jigang Zhang ${ }^{1,2, *}$, Wenyan Deng ${ }^{1}$ and Zhuwen Yue ${ }^{1}$ \\ ${ }^{I}$ School of Civil Engineering, Qingdao Technological University, Qingdao,Shandong, 266033, China \\ ${ }^{2}$ State Key Laboratory of Coastal and Offshore Engineering in Dalian University of Technology, Dalian, Liaoning, \\ 116023, China
}

\begin{abstract}
Because of its excellent energy dissipation capacity, friction damper has a wide application in engineering structure, while its use is restricted by constant frictional force. Piezoelectric ceramic actuator has electrochromic deformation ability, by the use of this advantage to combine piezoelectric ceramic actuator with friction damper to form piezoelectric friction damper. This paper conducts some experiments, firstly to study the force output performance, response time of ordinary piezoelectric friction damper, hysteretic behavior as well as its energy dissipation, secondly to study the performance of the Pall-typed piezoelectric friction damper which is consisted by Pall-typed frictional damper and piezoelectric ceramic actuator. The results show piezoelectric friction dampers have good force output capacity and they increase with the input voltage increases; the dampers have a quick response and a short response time; the hysteretic behaviors are stable, which almost has no relevance with loading frequency.
\end{abstract}

Keywords: Piezoelectric friction damper, Piezoelectric ceramic actuator, Pall damper, Response time, Hysteretic behavior.

\section{INTRODUCTION}

A typical friction damper is a passive energy dissipation device, its dissipation effect depends on friction force and slip displacement, and friction force is proportional to the friction coefficient and the bolt clamping force [1]. Under a large clamping force, small vibration will not lead to the damper to slip and dissipate energy; under a small clamping force, there will be a slip, but the total energy dissipation is not high $[2,3]$, which makes the friction damper to be greatly restricted in civil engineering.

Under this context, smart friction damper is put forward, which uses the micro-drive characteristics of new smart materials for adjusting bolt clamping force in real-time. Because of its simple structure, rapid response, make it become a new research focus of intelligent variable friction damper [4-7]. Actuators generally have magnetostrictive actuators, piezoelectric actuators, etc. Under magnetic fields, the former can change their length in milliseconds of time; the excitation field of the latter is electric field rather than the magnetic field.

In this paper, the performance of a common piezoelectric friction damper (PZT friction damper, called OPFD), formed by piezoelectric actuator (PZT actuator) and ordinary friction damper, was researched, and on this basis the PPFD is put forward which is composed by PZT actuator and Tshape core plate friction damper(called Pall-typed frictional damper) [8]. The paper conducted two experiments, one is to

*Address correspondence to this author at the School of Civil Engineering, Qingdao Technological University, Qingdao, Shandong, 266033, China; Tel: +86-532-85071218; Fax: +86-532-85071218;

E-mail: zhangjigang_hit@163.com test the response time and capability, output performance of the OPFD composed by PZT actuator and typical friction damper, another is to study the hysteretic behavior of the PPFD and some conclusions have been drawn.

\section{THE FIRST SET OF EXPERIMENTS}

The OPFD(seen in Figs. 1 and 2) used in the first set of experiments, is formed by a PZT actuator and an ordinary friction damper. The research mainly tests dynamic response time, response capability, output performance of the OPFD.

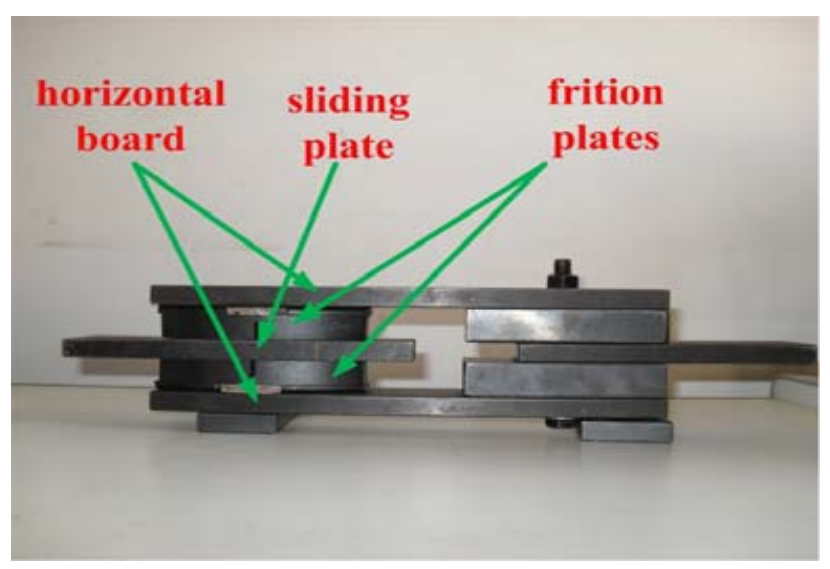

Fig. (1). The ordinary friction damper.

\section{Experimental Overview}

PZT actuator (Fig. 3) is imports from Germany, the voltage range of it is $0 \sim 150 \mathrm{~V}$, the relevant parameters are shown in Table $\mathbf{1}$. The friction damper is fabricated, actuator 


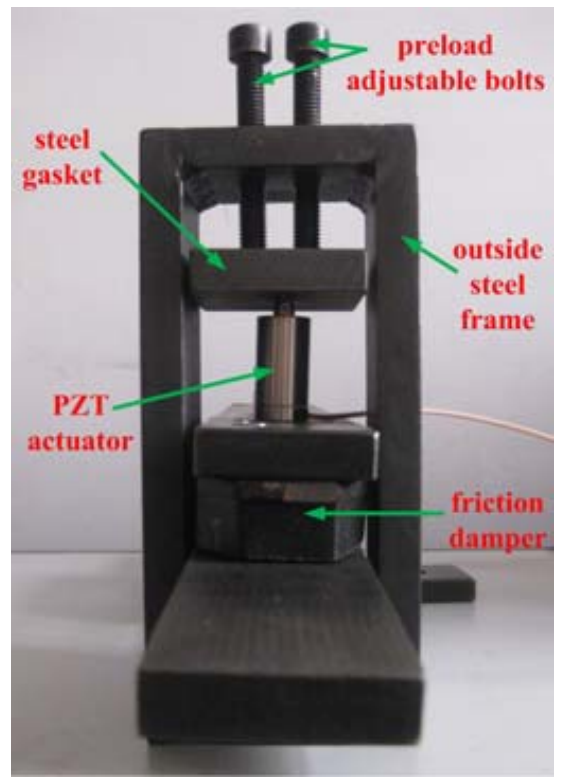

Fig. (2). The PZT friction damper(OPFD).

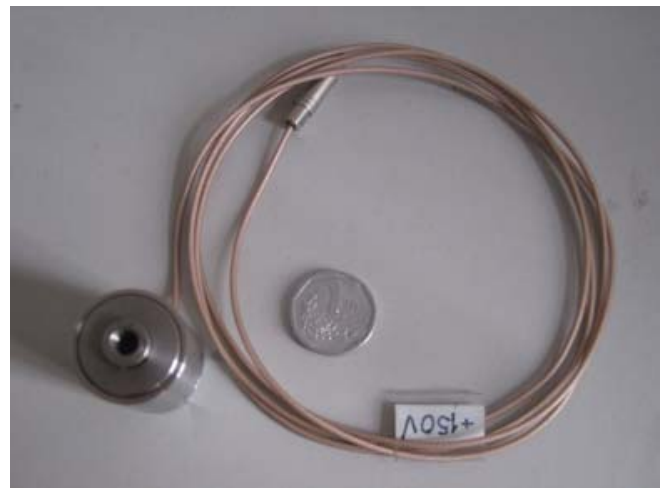

Fig. (3). PZT actuator.

power is HPV Series C-type piezoelectric actuator power, output voltage range is $0 \sim 150 \mathrm{~V}$ around.

Experiments are done on Shimadzu electronic tensile machine in building materials laboratory of QingDao Technological University. First, the OPFD is assembled, then make the sliding plates of both ends of it fix to the upper and lower chucks of electronic tensile machine. It is assured that the sliding plates of the OPFD is on the center line of the actuator in electronic tensile machine. In this way, the sliding plates can be leaded to move when electronic tensile machine works. Using the displacement to control during conducting the experiments, the speed is $0.5 \mathrm{~mm} / \mathrm{min}$. Using sensory equipment of electronic tensile machine to survey and gather the friction force and displacement of the PFD, which are saved in hard disk of computer.
Response time testing: fixed initial positive pressure, exerting load by the electronic tensile testing machine to create relative uniform motion between sliding plate and the two-sided friction plate(that is to reach a steady state), then driving the power, makes the actuator work, and tests time-varying damping force. The time that damping force from one steady state to another one is the OPFD response time.

\section{Experimental Results}

(1) Response capability: Damping force-time curves with voltage range of $30 \mathrm{~V} \sim 70 \mathrm{~V}$, square wave as input waveform, frequencies as $0.1 \mathrm{HZ}$ and $0.5 \mathrm{HZ}$, are shown in Figs. (4 and 5). From Fig. (4), PZT actuator has a strong response and a rapid response speed to the input waveform, but the output performance is not good, the reason maybe is that the stiffness of clamping device just too small, or PZT actuator deformation is too small and difficult to control.

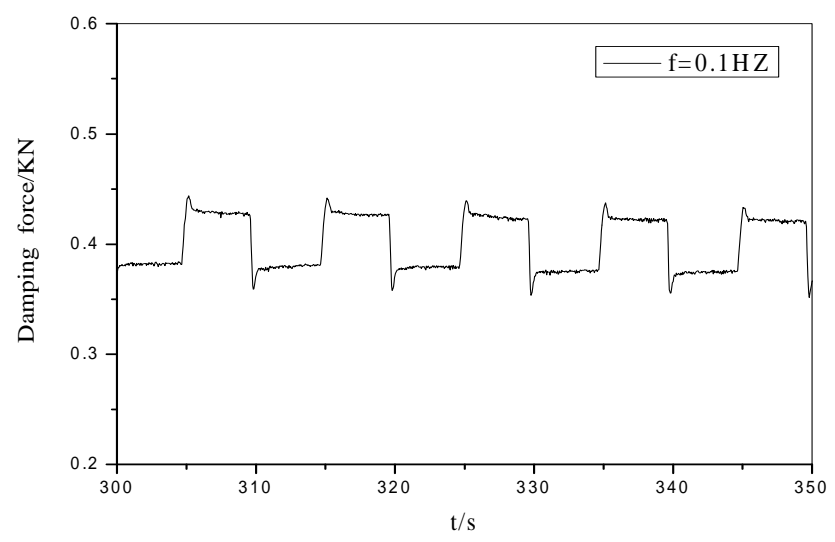

Fig. (4). Damping force-time curve.

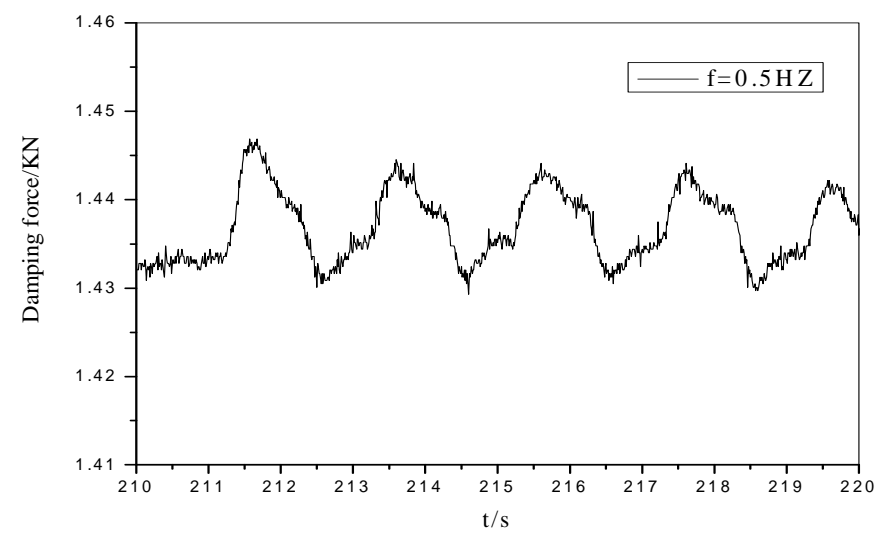

Fig. (5). Damping force-time curve.

Table 1. The Relevant Parameters of PZT Actuator

\begin{tabular}{|c|c|c|c|c|c|c|}
\hline Specification & Length & $\begin{array}{c}\text { Maximum Displacement } \\
\mu \mathrm{m} \pm 10 \%\end{array}$ & $\begin{array}{c}\text { Maximum } \\
\text { Output N }\end{array}$ & $\begin{array}{l}\text { maximum Tensile } \\
\text { Strength } N\end{array}$ & $\begin{array}{l}\text { Stiffness } \\
\mathrm{N} / \mu \mathrm{m}\end{array}$ & $\begin{array}{c}\text { Capacitance } \\
\mu \mathrm{F}\end{array}$ \\
\hline PSt150/20/18 VS25 & 37 & 25 & 11000 & 1500 & 500 & 11 \\
\hline
\end{tabular}


Compared Fig. (4) with Fig. (5), it shows that the response of this type actuator relates to the input voltage frequency, and the frequency faster, the response worse, so setting appropriate voltage frequency has an influence on response capability.

(2) Response time: Figs. (6 and 7) depict the response time of PFD under the same voltage(30 70V) and the same voltage frequency $(0.1 \mathrm{HZ})$, different loading speed. Compared the two charts, we can get:

(1) The response time of PZT actuator is $30 \mathrm{~ms}$ around, the relationship between response time and voltage change value, is little. PZT actuators are capacitive load, the greater cross-sectional area and the more stack, the capacitance will be greater and the corresponding response time will be longer, the response time is generally $0.1 \mathrm{~ms} \sim 10 \mathrm{~ms}$ [1].

(2) The response time of OPFD is about 0.8s in Fig. (6), while $0.3 \mathrm{~s}$ in Fig. (7), that is to say the faster relative motion between friction plates, the shorter response time (the loading speed reflects the relative sliding velocity between friction plates). The overall response time of OPFD lags behind PZT actuator, which maybe caused by response lag of the actuator power.

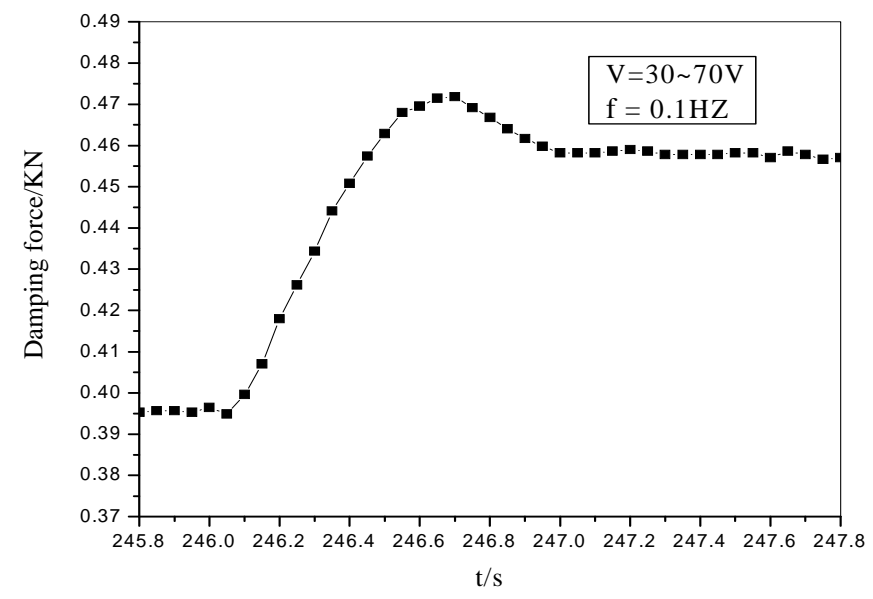

Fig. (6). Response time $(\mathrm{V}=0.5 \mathrm{~mm} / \mathrm{min})$.

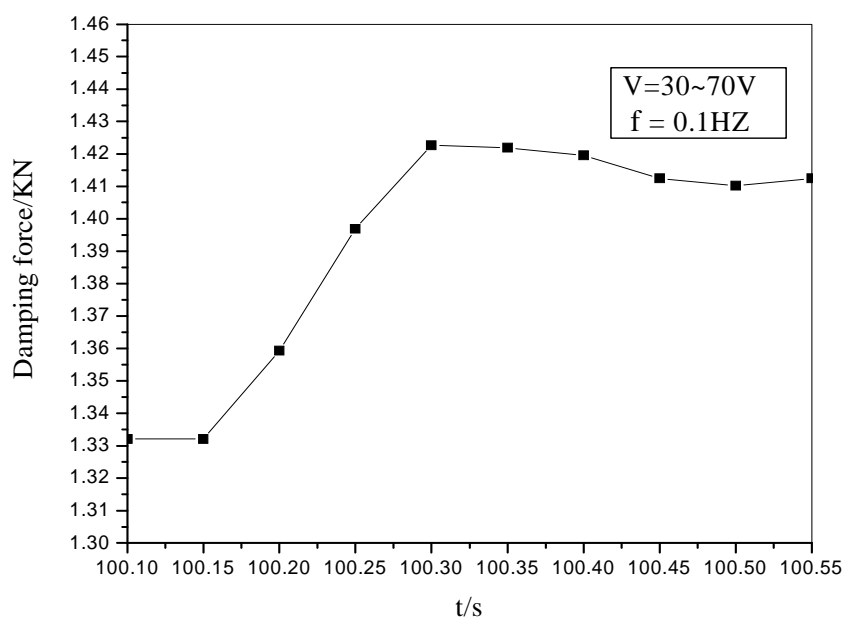

Fig. (7). Response time( $V=5 \mathrm{~mm} / \mathrm{min})$.
(3) The output performance of the PFD: The OPFD through the micro-drive characteristics of PZT actuator, adjust the pressure on friction damper in real-time, and enhance the frictional energy dissipation, with some characteristics as simple structure and fast response. Experimental results show that PZT actuator with good electrochromic deformation can quickly adjust positive pressure between the friction plates when they work, then adjust the friction force (that is, the damping force of damper) [1]. The output of PZT actuator and voltage have a basic linear relationship, and the pre-stress has a certain impact on the output performance of the actuator, to see references [9].

The following pictures figure out the changes in damping force under voltage frequency as $0.5 \mathrm{HZ}$, several different voltage (As the fastening forces are re-applied in each experiment, it can not guarantee the accuracy of the working conditions is the same). From the charts, it is easy to see that with the increase of input voltage, damping force (friction) increases. In Fig. (8), the damping force output increases $15 \mathrm{~N}$ approximately when the voltage is $20 \mathrm{~V}$; in Fig. (9), the

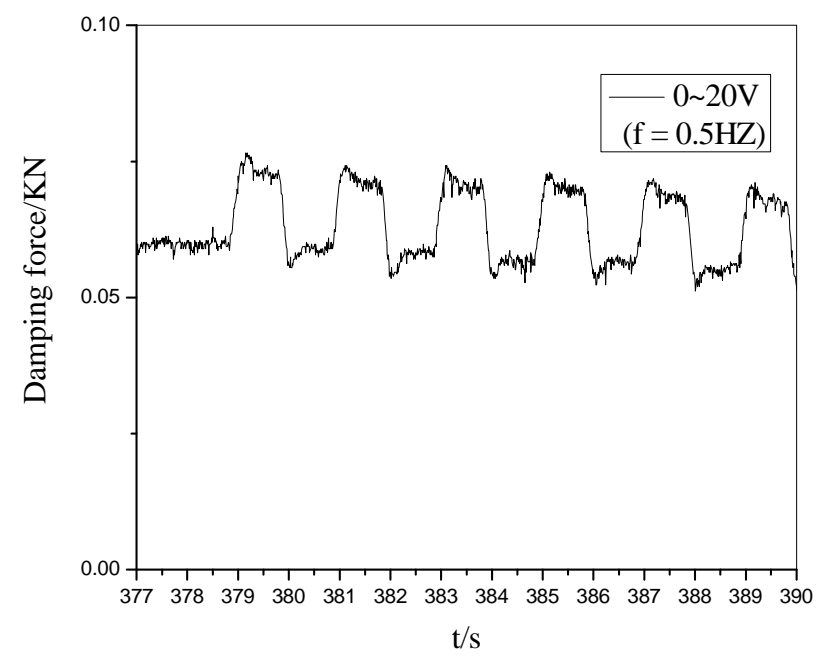

Fig. (8). Voltage(0 20V).

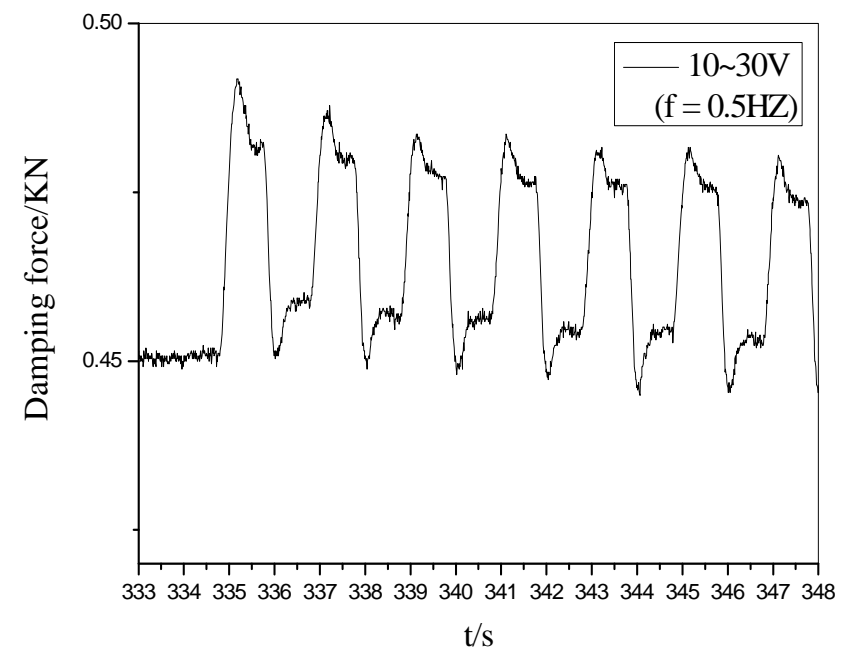

Fig. (9). Voltage(10 30V). 
force output increases $35 \mathrm{~N}$ around with the voltage of $30 \mathrm{~V}$; in Fig. (10), the force output increases $80 \mathrm{~N}$ around with the voltage of $60 \mathrm{~V}$, the reason is that the PZT actuator rapidly deform after driving the power, that is equivalent to increase the positive pressure of the damper, so as to enhance the friction damping force of the damper.

\section{THE SECOND SET OF EXPERIMENTS}

In this experiment, the ordinary friction damper replaced by T-shaped core plate friction damper[8] combines with PZT actuator, to form a new PFD called PPFD, then the PPFD is mounted on a steel frame, and its hysteretic behavior and energy dissipation are studied.

\section{Test Equipments}

(1) The PPFD and steel frame: This PPFD, which is different from the above OPFD, constituting T-shape core plate friction damper with PZT actuator, uses in steel frame. It adopts 3 pieces of T-sliding plate that are double-sided friction and connects with steel frame by double-angle steel brace. The PPFD physical construction is shown in Fig. (11), steel frame physical photo is shown in Fig. (12).

(2) Other test equipments: (1) MTS machine: MTS machine at 25 tonnage, use displacement control that is set to $4 \mathrm{~mm}, 8 \mathrm{~mm}$; loading frequency $f$ is $1 / 150,1 / 75,1 / 50$, $1 / 25 \mathrm{HZ}$; loading waveform adopts sine wave, the computer automatically collects damper data and stores in the hard disk.

(2) Actuator power: Models are the same with the above, using manual control input voltage that does not change with time.

(3) Torque wrench: using a torque wrench to control the initial tightening force of damper, $10 \mathrm{Nm}, 20 \mathrm{Nm}, 40 \mathrm{Nm}$ are used as three initial tightening torques in the experiments.

(4) Dynamic strain acquisition instrument: In this study, stress and strain data is collected by the dynamic strain acquisition instrument, and stores in hard disk of computer.

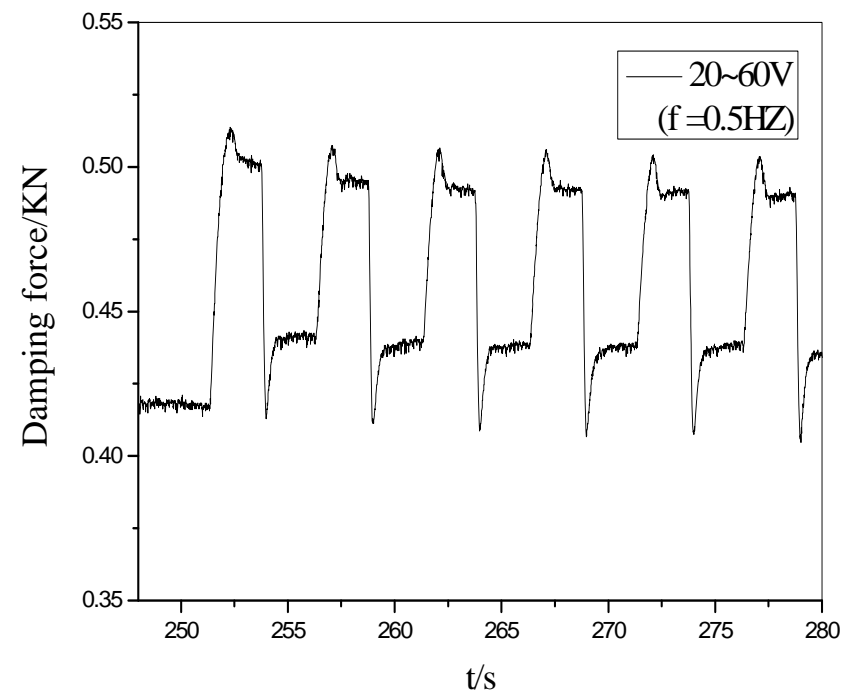

Fig. (10). Voltage(20 60V).

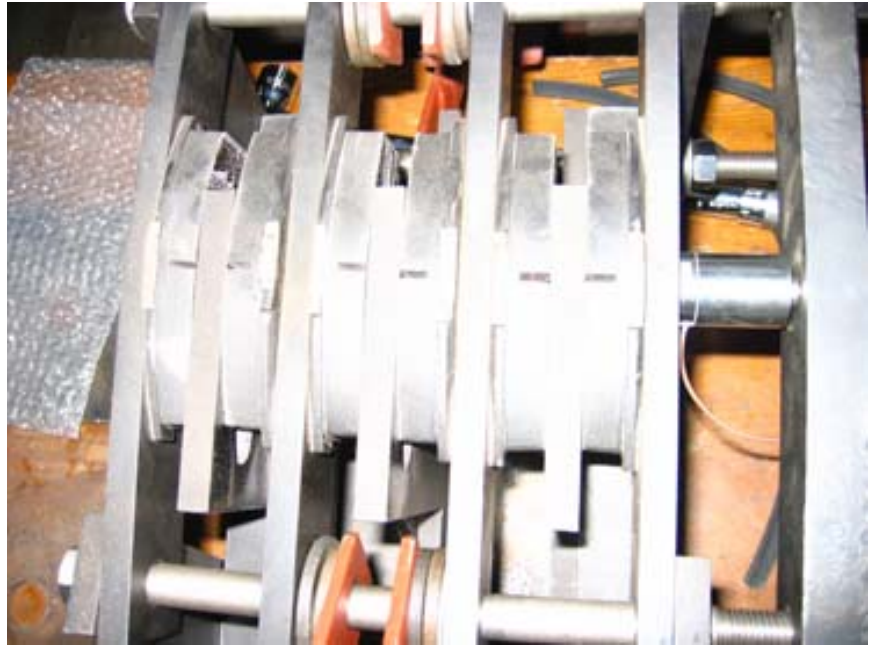

Fig. (11). PPFD physical construction.



Fig. (12). Steel frame physical map.

\section{Experimental Methods}

This experiments are divided into two stages, the first is to study the hysteretic behavior of the PPFD under passive state(there is no voltage); the second stage is also to study its hysteretic behavior under semi-active state(case of drive power).

\section{Experimental Results}

(1) Hysteretic behavior of the PPFD under passive state. The following charts figure out the hysteretic behavior curves of the PPFD under $8 \mathrm{~mm}$ of displacement, $10 \mathrm{Nm}$ of tightening torque, and different loading frequency.

From above charts, we can conclude that: (1) Hysteresis loops of the PFD are basically stable, hysteretic behavior is good; (2) The increase of frequency leads to some fluctuation of hysteresis loop, which have little effect on its performance; (3) Compared the charts in Fig. (13), it shows that the greater the preload, the greater sliding friction force, which lead to the PFD sliding more difficultly, thus setting the appropriate preload has great influence on energy 
dissipation of the PFD; (4) With the bigger displacement amplitude, the hysteresis loop is more full and energy dissipation is more better. As shown in Fig. (14), the slide is very small when load displacement is $4 \mathrm{~mm}$, hysteresis loop is narrower and energy dissipation capacity is worse.

(2) Hysteretic behavior of the PPFD under semi-active state. This stage is mainly to test hysteretic behavior of the PPFD after driving the power. Because of experimental conditions, the piezoelectric actuator power drives with manual control; tightening torque is $10 \mathrm{Nm}$; voltages are taken as $30 \mathrm{~V}, 60 \mathrm{~V}, 90 \mathrm{~V}$; other loading conditions are the same with the former. The following figures show hysteresis loops of the PPFD when displacement of external excitation is $8 \mathrm{~mm}$ and $4 \mathrm{~mm}$, loading frequency of it is $1 / 75 \mathrm{HZ}, 1 / 25 \mathrm{HZ}$.

In theory, the output of the actuator increases as the voltage increases, the friction force of the damper also increases gradually [9]. From the experimental results (seen in Figs. 15-17), as the voltage increases, the friction force increases, but it does not show a greater difference(almost similar to overlap). It maybe due to the displacement of PZT actuator is too small, the largest is only $25 \mathrm{um}$; the preload
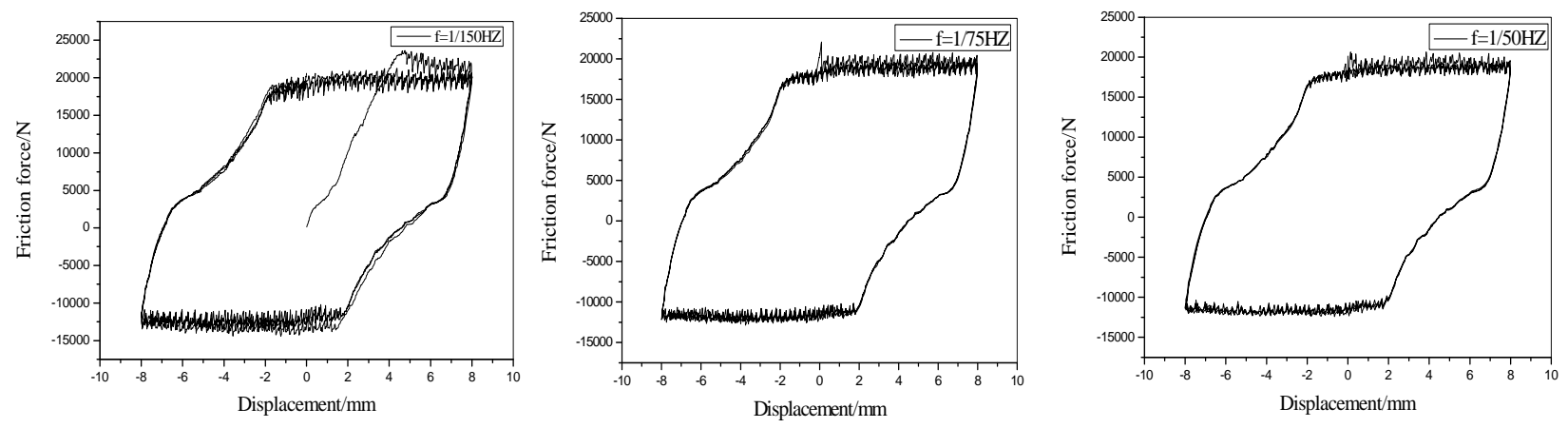

\section{a)tightening torque $10 \mathrm{Nm}$}

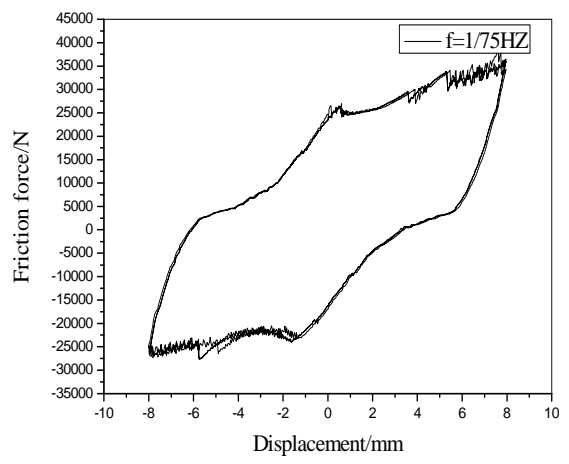

\section{b)tightening torque $40 \mathrm{Nm}$}

Fig. (13). Hysteretic loop(displacement 8mm).
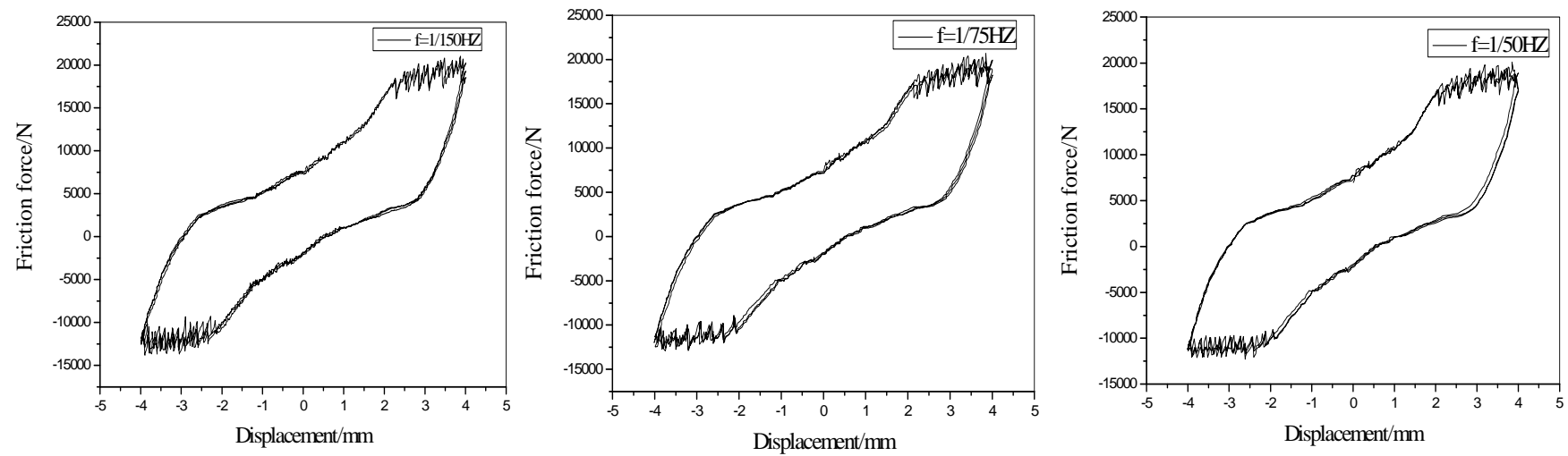

Fig. (14). Hysteretic loop (displacement 4mm; tightening torque $10 \mathrm{Nm}$ ). 
setting is not sufficient to eliminate the gap between the friction plates, which should be paid attention in subsequent trials.

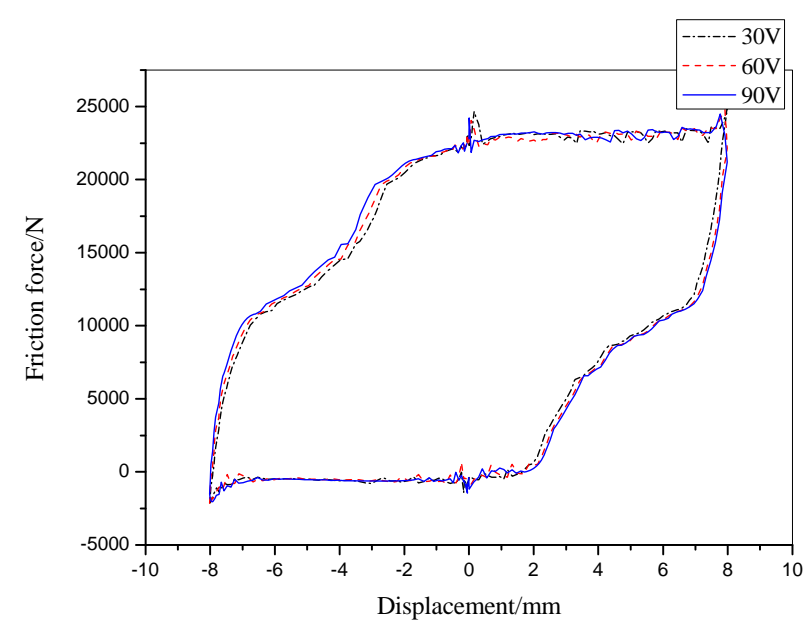

Fig. (15). Hysteretic loop $(8 \mathrm{~mm}, \mathrm{f}=1 / 75 \mathrm{HZ})$.

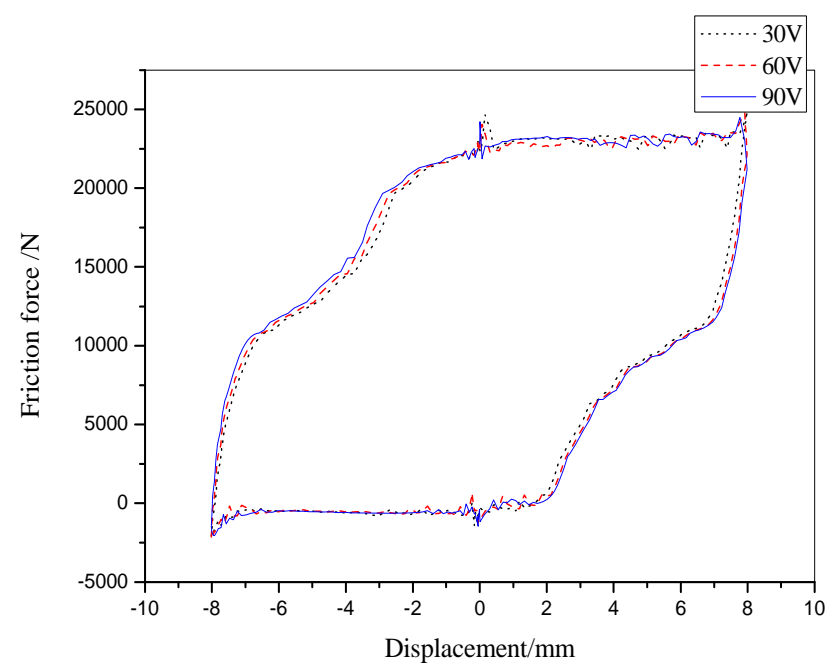

Fig. (16). Hysteretics loop $(8 \mathrm{~mm}, \mathrm{f}=1 / 25 \mathrm{HZ})$.

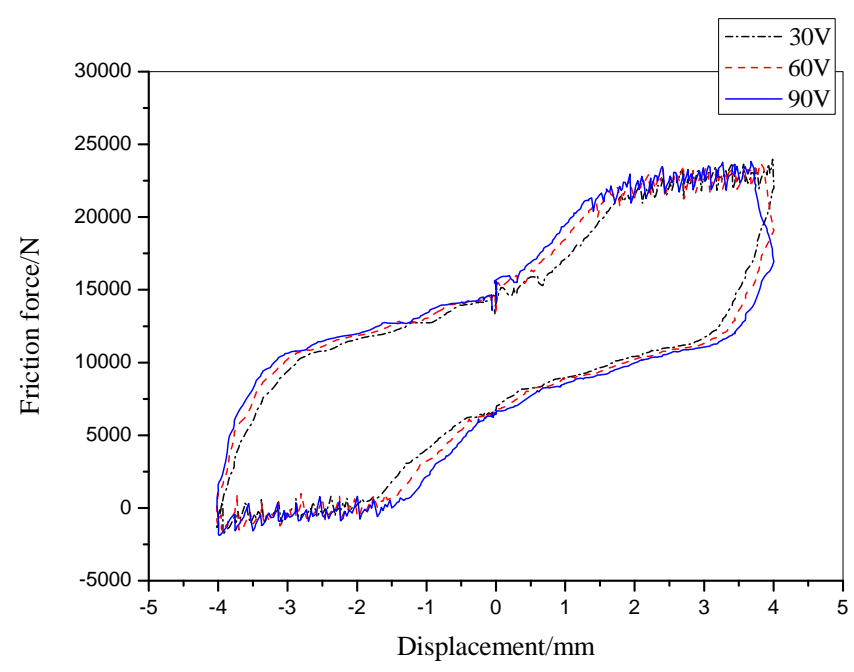

Fig. (17). Hysteretic loop (4mm, f=1/75HZ).

\section{The Energy Dissipation Capacity of the PPFD}

The area surrounded in a circular of hysteretic loop, is the energy dissipation of the PFD within a circular, which can express as $E_{d}$ :

$E_{d}=\int_{0}^{2 \pi / \omega} f \cdot d x$

In the equation, $\omega$ is the circular frequency of excitation, $f$ is the friction force of the damper.

In fact, the size of energy dissipation is the area surrounded by the hysteretic loop, and energy dissipation of the damper increases as the input voltage increases. Under the circumstances which the loading frequency and voltage are the same, energy dissipation of the damper increases with the increase of loading amplitude. Meanwhile, with the same conditions of the loading amplitude and voltage, the hysteretic loop of the damper is stable and independent with the loading frequency, that is energy dissipation of the damper is independent with the loading frequency.

\section{CONCLUSIONS}

In this paper, the performances of the OPFD and PPFD are analyzed, and some conclusions are obtained:

(1) Hysteretic loops of PZT friction damper (PFD) are full, with good dissipation performance.Under passive state, the hysteretic loops is full, stable and does not change with loading frequency. Under semi-active state, the hysteretic loops is still full and stable, showing good robustness.

(2) The friction force of damper increases as the actuator's output increases, which increases with increase of voltage.

(3) If the load frequency and voltage is the same, respectively, the energy dissipation of PZT friction damper would increase with the increase of load amplitude.

(4) The friction force of PZT friction damper and the energy dissipation are almost affected by the load frequency.

\section{OUTLOOK}

The PFD has good stability, robustness and a capacity of fail-safe, which makes it has a wide application prospect in civil engineering structures, but it also restricts by many factors, such as: the deformation of PZT actuator is too small, output capacity is not large, the response time is lag, etc; a significant piezoelectric effect needs a high electric field, even if the PZT actuator is laminated, the maximum voltage also needs about100V 300V[1]; the cost of PZT actuator is very high, etc. In the future, we should focus on overcoming these limitations, to make the PFD has a more broader application prospect.

\section{CONFLICT OF INTEREST}

\section{Declared none.}

\section{ACKNOWLEDGEMENTS}

The authors gratefully acknowledge the financial support provided by National Natural Science Foundation of China through grant number 50809032, Shangdong Province 
Distinguished Young and Middle-Aged Scientists Research Award Fundation through grant number BS2010HZ008, Open Foundation for State Key Laboratory of Coastal and Offshore Engineering in Dalian University of Technology through grant number LP1009, China Postdoctoral Science Foundation the 2nd special funded project through grant number 200902540 and China Postdoctoral Science Foundation funded project through grant number 20070421051.

\section{REFERENCES}

[1] X. Guan, G. Fei, Y. Wu, and J. Ou, "Experimental study on smart friction damper based on smart micro drive actuator", J. Shock Vib., vol. 27, pp. 18-22, Oct. 2008, in Chinese.

[2] P. Colajanni, and M. Papia, "Seismic response of braced frames with and without friction dampers", Eng. Struct., vol. 17, no. 2, pp. 129-140, Feb. 1995.
[3] A. Nishitani, Y. Nitta, and Y. Ishibashi, "Structural control based on semi-active variable friction dampers", In: Proceedings of the 12th World Conferences on Earthquake Engineering, Auck land: New Zealand, 2000, pp. 265-276.

[4] P. Dupont, P. Kasturi, and A. Stokes, "Semi-active control of friction dampers", J. Sound Vib., vol. 202, no. 2, pp. 203-218, 1997.

[5] A.K. Agrawal, and J.N. Yang, "A semi-active electromagnetic friction damper for response control of structures", In: ASCE Proceedings of the 2000 Structures Congress and Exposition, Philadelphia, PA: USA, 2000, pp. 218-225.

[6] J. Ou, Structural Vibration Control: Active, Semi-active and Intelligent Control, Science Press, Beijing, 2003, in Chinese.

[7] G. Chen, "Behavior of piezoelectric friction dampers under dynamic loading", Proc. SPIE, no. 3988, pp. 54-63, 2000.

[8] B. Wu, J. Zhang, M. Williams, and J. Ou, "Hysteretic behavior of improved Pall-typed frictional dampers", Eng. Struct., vol. 27, pp. 1258-1267, 2005.

[9] D. Zhao, and H. Li, "Experimental investigation of piezoelectric friction damper", Piezoelecter. Acoustoopt., vol. 31, pp. 60-62, Feb. 2009.

(C) Zhang et al.; Licensee Bentham Open.

This is an open access article licensed under the terms of the Creative Commons Attribution Non-Commercial License

(http://creativecommons.org/licenses/_by-nc/3.0/) which permits unrestricted, non-commercial use, distribution and reproduction in any medium, provided the work is properly cited. 